\title{
FZG Gear Efficiency and Pin-on-Disc Frictional Study of Sintered and Wrought Steel Gear Materials
}

\author{
Xinmin $\mathrm{Li}^{1} \cdot$ Ulf Olofsson ${ }^{1}$
}

Received: 27 January 2015/ Accepted: 21 August 2015

(C) Springer Science+Business Media New York 2015

\begin{abstract}
Load-dependent power loss is a major contributor to power loss in gear transmission systems. In this study, pin-on-disc frictional and FZG efficiency experiments were conducted with powder metallurgy (Distaloy $\mathrm{AQ}+0.2 \% \mathrm{C})$ and wrought material $(16 \mathrm{MnCr} 5)$ combinations. The gear mesh torque loss from gear efficiency tests and the friction coefficient from the pin-on-disc tests were then compared. The trend for both test series was the same. The combination of $16 \mathrm{MnCr} 5$ in contact with Distaloy $\mathrm{AQ}+0.2 \% \mathrm{C}$ shows the lowest coefficient of friction and gear mesh torque loss, followed by the combination of Distaloy $\mathrm{AQ}+0.2 \% \mathrm{C}$ in contact with itself and finally the combination of $16 \mathrm{MnCr} 5$ in contact with itself.
\end{abstract}

Keywords Friction - Gear mesh torque loss - Powder metallurgy $\cdot$ FZG gear test rig $\cdot$ Pin-on-disc

\section{List of symbols}

PM Powder metallurgy

RS $\quad 16 \mathrm{MnCr} 5$

AQ Distaloy AQ $+0.2 \% \mathrm{C}$

A-B Disc-pin/gear-pinion

$T_{c} \quad \operatorname{Load}(\mathrm{N} \mathrm{m})$

$T_{\mathrm{T}} \quad$ Total torque loss $(\mathrm{N} \mathrm{m})$

$\omega \quad$ Rotation speed (rpm)

$t \quad$ Time (s)

This article is part of the Topical Collection on STLE Tribology Frontiers Conference 2014.

\section{Xinmin Li}

xinmin@kth.se

1 Department of Machine Design, Royal Institute of Technology (KTH), Brinellvägen 83, 10044 Stockholm, Sweden $\eta \quad$ Dynamic viscosity (Pas)

$P_{\mathrm{T}} \quad$ Total power loss (W)

$P_{\text {mesh }} \quad$ Load-dependent power loss (W)

$P_{\text {spin }} \quad$ Load-independent power loss (W)

$M_{r r} \quad$ Rolling friction moment (Nm)

$T_{1} \quad$ Load-dependent torque loss (Nm)

$\lambda \quad$ Surface energy $(\mathrm{J})$

$\rho, \rho_{0} \quad$ Density

$E, E_{0} \quad$ Young's modulus (Gpa)

$v, v_{0} \quad$ Poisson's ratio

$z \quad$ Number of teeth

$m_{n} \quad$ Normal module

$B \quad$ Gear width (mm)

$\alpha \quad$ Pressure angle

$d_{\mathrm{b}} \quad$ Base diameter $(\mathrm{mm})$

$d_{\mathrm{a}} \quad$ Tip diameter $(\mathrm{mm})$

$d_{\mathrm{f}} \quad$ Root diameter $(\mathrm{mm})$

$a \quad$ Centre distance ( $\mathrm{mm})$

$\beta \quad$ Helix angle

$M_{\mathrm{sl}} \quad$ Sliding friction moment (Nm)

$T_{\text {bearing }} \quad$ Load-dependent bearing loss (Nm)

$T_{a b} \quad$ Adhesive energy of surface $a$ and $b(\mathrm{~J})$

\section{Introduction}

Environmental concerns such as energy utilization and air pollution have made the efficiency of gear systems an increasingly important research topic. Power loss in gearboxes is usually divided into load-dependent and load-independent power losses $[1,2]$. The load-independent losses are related to moving parts immersed in the lubricant, while the load-dependent losses result from contacting bodies moving relative to each other. Load-independent 
losses depend mainly on the lubricant, speed and part geometry, whereas load-dependent power losses are affected by factors such as gear mesh efficiency.

Several experimental studies have been published related to gear mesh efficiency. Petry-Johnson et al. [2], Naruse et al. [3, 4] and Maghales [5] showed that reducing the module can have a significant influence on gear mesh losses because of the reduced sliding friction. Martins et al. [6] measured the average friction coefficient of dip-lubricated FZG gears and reported that the friction coefficient decreases with increasing rotational speed and increases with transmitted torque. Britton et al. [7] reported that using an isotropic chemical polishing technique to reduce the average surface roughness height from 0.4 to $0.05 \mu \mathrm{m}$ reduced gear mesh power loss by between 20 and $30 \%$.

Friction force can be defined as the resistance encountered by one body moving over another body. This definition covers both sliding and rolling bodies. The resistive force, which is parallel to the direction of motion, is called the friction force. If solid bodies are forced together, the static friction force is equal to the tangential force required to initiate sliding between the bodies. The kinetic friction force is then the tangential force required to maintain sliding. Kinetic friction is generally lower than static friction. For sliding bodies the friction force, and thus the coefficient of friction (friction force divided by normal force), depends on three different mechanisms in dry and mixed lubricated conditions: deformation of asperities, adhesion of the sliding surfaces and ploughing caused by deterioration particles and hard asperities [8]. The coefficient of friction can be reduced by changing the surface topography to decrease ploughing and the deformation of asperities or by changing the hardness difference between the contacting bodies. The adhesive friction may be reduced by having dissimilar materials or introducing alloy elements that reduce the surface energy [9].

It has been shown that controlled texturing on a tribological surface can contribute to friction reduction at sliding contact interfaces. One of the presumed effects of surface texturing under boundary lubrication conditions is that micro-dimples may act as fluid reservoirs and play a role in promoting the retention of a lubricating film. By using pinon-disc tests, Wakuda [10] verified the effect of microdimples on the frictional properties of a silicon nitride ceramic on hardened steel and successfully reduced the friction coefficient from 0.12 to 0.10 under lubricated conditions. Using reciprocating sliding of a ball-bearing steel against textured diamond-like carbon (DLC) surfaces, Pettersson [11] showed that under boundary lubrication conditions, some textured DLC surfaces exhibited excellent performance. In pin-on-disc tests, Kovalchenko [12] showed that the beneficial effects of micro-dimples are more pronounced at higher speeds and with higher viscosity oil.
Due to the inherent porosity of the material, gears manufactured from powder metallurgy materials will have different mechanical properties that affect the Young's modulus and Poisson's ratio. In addition, the pores of the surface and the near-surface layer may influence lubrication properties if the porosities can act as oil reservoirs. The different alloying elements used in powder metallurgy materials may also influence the surface layer and help prevent adhesive forces. Recently, Li et al. [13] compared sintered and standard gear materials in a pin-on-disc study simulating the loading conditions of load stage 5 in a FZG gear test rig. The results showed that the lowest coefficient of friction was obtained with a sintered pin sliding on a standard wrought gear material disc, compared to tests with sintered on sintered contacting pairs and also standard wrought on standard wrought gear material.

In this study, a further test of the results of Li et al. [13] was set up in a FZG efficiency gear test rig. In this test series, the efficiency was evaluated over a wider speed range but for the same maximum contact pressure as previous pin-on-disc tests using the same material combinations. Additional tests at higher loading conditions were performed in the FZG gear test rig in combination with a new pin-on-disc test series that also evaluated the material combinations at a lower sliding speed to study the boundary lubrication contact conditions for these material combinations in more detail. For rolling and sliding contact such as gears, sliding is the main contributor of power consumption. Nowadays, more and more tribologists are using pin-on-disc/ball-on-disc experiment to simulate the sliding part of rolling-sliding contact because of its economical, time saving and convenience. But whether it is reasonable is doubted by lots of researchers and need to be studied. In this study, the mesh torque loss of FZG efficiency test and friction coefficient of pin-on-disc experiment are compared to manifest it.

\section{Experimental Set-Up}

Three different material combinations were tested in a pinon-disc machine and an FZG gear efficiency test machine. The test materials were $16 \mathrm{MnCr} 5$ (RS) and Distaloy $\mathrm{AQ}+0.2 \% \mathrm{C}(\mathrm{AQ})$. The tested material combinations were RS-RS, RS-AQ and AQ-AQ. Note that RS and AQ will be used in the remainder of this paper to identify $16 \mathrm{MnCr} 5$ (RS) and Distaloy $\mathrm{AQ}+0.2 \% \mathrm{C}$ (AQ), respectively. Table 1 presents the chemical composition of the two tested materials and Table 2 the mechanical properties. AQ was sintered for $45 \mathrm{~min}$ at $1120^{\circ} \mathrm{C}$ in a $90 \%$ nitrogen and $10 \%$ hydrogen atmosphere. The standard gear steel, $16 \mathrm{MnCr} 5$, is well-known wrought steel with easily identified elastic properties. For the sintered 
Table 1 Chemical composition (mass \%) of RS gears and AQ gears

\begin{tabular}{llllllllll}
\hline & $\mathrm{Ni}$ & $\mathrm{Mn}$ & $\mathrm{Fe}$ & $\mathrm{C}$ & $\mathrm{S}$ & $\mathrm{P}$ & $\mathrm{Si}$ & $\mathrm{Cr}$ & $\mathrm{Mo}$ \\
\hline $\mathrm{RS}$ & - & $1-1.3$ & $96.95-98.78$ & $0.14-0.19$ & $\leq 0.035$ & $\leq 0.025$ & 0.4 & 1.1 & - \\
$\mathrm{AQ}$ & 0.5 & 0.5 & 98.8 & 0.2 & - & - & - & - & - \\
\hline
\end{tabular}

Table 2 Mechanical properties and surface roughness of the specimens

\begin{tabular}{lll}
\hline & RS & AQ \\
\hline Young's modulus $(\mathrm{GPa})$ & 210 & 154 \\
Poisson's ratio & 0.3 & 0.28 \\
RMS surface roughness $($ disc $)(\mu \mathrm{m})$ & 0.06 & 0.06 \\
RMS surface roughness $($ pin $)(\mu \mathrm{m})$ & 0.09 & 0.09 \\
\hline
\end{tabular}

steels, the situation is more complicated. These materials are porous, and how they are manufactured determines their porosity and thus their density and mechanical properties. According to Beiss [14], the elastic properties of powder metal steel materials can be calculated using the following formulas:

$E=E_{0}\left(\rho / \rho_{0}\right)^{3.4}$

$v=\left(\rho / \rho_{0}\right)^{0.16}\left(1-v_{0}\right)-1$

where $\rho_{0}, E_{0}$ and $v_{0}$ are the density, Young's modulus and Poisson's ratio of solid steel, respectively.

The lubricant used in both test set-up was BP Castrol Syntrans $75 \mathrm{~W}-80$, which is a gear lubricant used in truck gearboxes. Table 3 presents the main characteristics of the lubricant. The A-B formulation will be used in the remainder of this paper to identify the materials of disc and pin (or pinion and gear in gear efficiency tests), the former letter identifying the disc material (or pinion material) and the latter the pin material (or gear material). The pin-ondisc and FZG gear efficiency tests were designed to reach the same loading level in terms of contact pressure. That is, load stages 5 and 7 of the FZG gear test rig correspond to contact pressures of 900 and $1080 \mathrm{MPa}$.

\subsection{Pin-on-Disc Experiment}

\subsubsection{Pin-on-Disc Experimental Set-Up}

A pin-on-disc machine was used to simulate the sliding part of the gear contact, see Fig. 1. The pin-on-disc machine comprised a horizontal rotating disc and a calibrated dead-weight-loaded pin. This pin-on-disc machine is described in more detail in Zhu et al. [15] and Bergseth et al. [16], who studied the influence of environmental conditions and iron oxides on the coefficient of friction between wheel and rail materials.

In the present test, the tip of the pin was a non-rotating half-sphere with radius of $5 \mathrm{~mm}$ (Fig. 1). The same final manufacturing methodology (grinding) was used on all pin and disc specimens resulting in a similar surface topography. The friction force was automatically measured in the pin-on-disc machine using a load cell with a measurement uncertainty better than $0.5 \%$. Here the load cell used is Z6FC3 (type) produced by HBM, and the load range of it is $0.09-1000 \mathrm{~N}$. The friction coefficient was calculated from the measured friction force divided by the normal load exerted on the pin by the testing machine's dead weight. The friction coefficients are shown in terms of mean value and standard deviation.

\subsubsection{Test Procedure}

The test matrix for the pin-on-disc experiment is shown in Table 4. Each test was performed twice to ensure repeatability. The test results from $900 \mathrm{MPa}$ were previously presented in Li et al. [13]. For the higher maximum contact pressure of $1080 \mathrm{MPa}$, the speed ranges were chosen differently to explore more of the boundary lubrication regime. The maximum contact pressures correspond to load stages 5 and 7 in the FZG gear tests.

\subsection{Gear Efficiency Experimental Set-Up}

\subsubsection{FZG Gear Test Rig}

The test rig used in this experiment utilizes the power loop principle, also known as four-square or back-to-back configuration, to provide a fixed torque (load) to a pair of precision test gears. As shown in Fig. 2 [17], the gear test
Table 3 The main characteristics of the lubricant

\begin{tabular}{ll}
\hline Lubricant name & BP Castrol Syntrans $75 \mathrm{~W}-80$ \\
\hline Kinematic viscosity at $40^{\circ} \mathrm{C}\left(\mathrm{mm}^{2} / \mathrm{s}\right)$ & 64.1 \\
Kinematic viscosity at $90{ }^{\circ} \mathrm{C}\left(\mathrm{mm}^{2} / \mathrm{s}\right)$ & 18 \\
Pressure-viscosity coefficient $\alpha\left(\mathrm{mm}^{2} / \mathrm{N}\right)$ & $1.79 \times 10^{-8}$ \\
Dynamic viscosity $\eta($ Pas $)$ & $42.7 \times 10^{-3}$ \\
\hline
\end{tabular}


Fig. 1 Sketch of pin-on-disc machine (left) and photograph of test specimens (right)
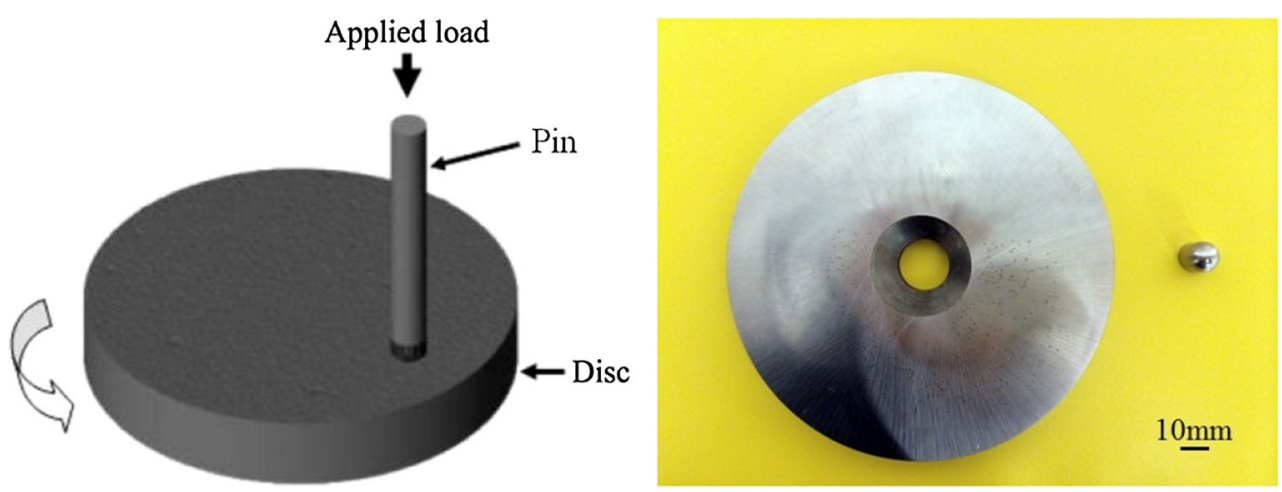

Table 4 Pin-on-disc test matrix

\begin{tabular}{llcl}
\hline Disc material & Pin material & Maximum contact pressure $(\mathrm{MPa})$ & Speed $(\mathrm{m} / \mathrm{s})$ \\
\hline RS & RS & 900 & 4 and $0.5[13]$ \\
RS & AQ & 900 & 4 and $0.5[13]$ \\
AQ & AQ & 900 & 4 and $0.5[13]$ \\
RS & RS & 1080 & 0.1 and 0.5 \\
RS & AQ & 1080 & 0.1 and 0.5 \\
AQ & AQ & 1080 & 0.1 and 0.5 \\
\hline
\end{tabular}

rig consists of a slave gearbox and test gearbox connected by two shafts. One shaft has a load clutch to apply the load. The test gearbox contains a system for heating the test oil and a water-cooling system to assist in cooling the oil to the required starting temperature. A temperature sensor, which controls the heating system according to the preset temperature, is located in the side of both the gearbox and slave gearbox. The test rig is powered by an electric motor at variable speeds up to $4000 \mathrm{rpm}$ and two directions of rotation. The transmitted torque $\left(T_{\mathrm{C}}\right)$, torque loss $\left(T_{\text {total }}\right)$, rotating speed $(\omega)$ and lubricant temperature $(T)$ are automatically measured and recorded as functions of time $(t)$. The torque (load) is applied with a spindle loading device, and the FZG gear test rig has 14 load stages. The use of this rig for efficiency studies is described in detail in Sjöberg et al. [18]. An uncertainty analysis of this rig for efficiency

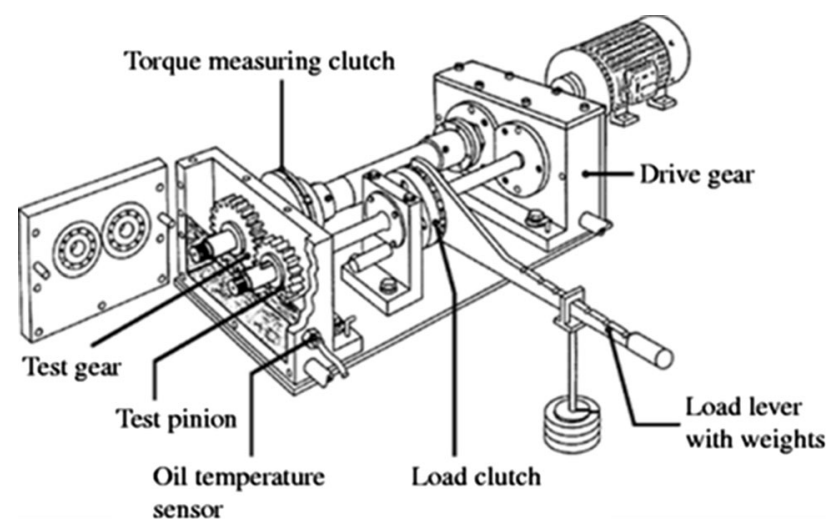

Fig. 2 Schematic layout of FZG test rig [17] studies by Andersson et al. [19] found the uncertainty in the torque measurements to be less than $0.5 \%$.

\subsubsection{Test Specimens and Lubricant}

The gear specimens used in this experiment are type $\mathrm{C}$ gears (with tip relief) as presented in Fig. 3. Type $\mathrm{C}$ gears are standard gears for FZG gear efficiency experiment. The main parameters and manufacturing characteristics of the specimens are shown in Table 5.

\subsubsection{Test Procedure}

All the tests were performed using the same procedure with new specimens. Running-in was done for $4 \mathrm{~h}$ at load stage

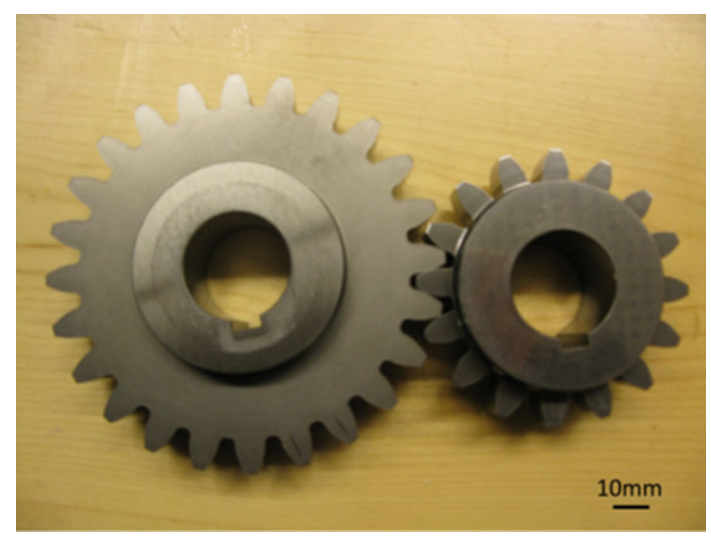

Fig. 3 Experimental test gears 
5 (applied torque $94 \mathrm{Nm}$ ) with rotating speed of $87 \mathrm{rpm}$ at a controlled temperature of $90^{\circ}$. Both running-in and efficiency experiments used the same lubricants. Both test gearbox and slave gearbox contained $1500 \mathrm{ml}$ lubricant. After running-in, the efficiency tests were done according to the test procedures shown in Table 6 for the different gear material combinations. Three different material gear combinations, eight different speeds and three loads were tested for $5 \mathrm{~min}$ each at the controlled lubricant temperature of $90^{\circ}$. The pitch-line velocities tested were $0.5,1,2$, $3.2,8.3,10,15$ and $20 \mathrm{~m} / \mathrm{s}$. The loads are $0,94.1$ and $183.4 \mathrm{Nm}$. Each test was performed three times to ensure repeatability.

\subsubsection{Gear Mesh Torque Loss Calculation from Measured Torques}

The calculation procedure used is that of Andersson et al. [19], but for clarity, it is presented here too. Because of the complex mechanical and fluid mechanical interactions in dip-lubricated gearboxes, there are a large number of power loss sources such as gear tooth mesh loss, air windage losses, oil churning loss, rotating seal losses and bearing losses. Gear torque losses are divided into loaddependent and load-independent power losses. The loadindependent losses are related to moving parts immersed in the lubricant, and the load-dependent power losses result from contacting bodies with relative movement. The loadindependent power losses are shown in Eq. (3). The main sources of frictional losses are the gears and the roller bearings.

$T_{\mathrm{T}}=T_{\text {load-dependent }}+T_{\text {load-independent }}$

where $T_{\mathrm{T}}$ is the measured total torque loss. $T_{\text {load-dependent }}$ is the load-dependent torque loss including gear tooth mesh loss and friction losses of seals and bearings.
$T_{\text {load-independent }}$ is the load-independent power loss including oil churning loss, air windage loss and rotating seal and bearing losses. In order to distinguish load-dependent and load-independent torque loss experimentally, a two-step measurement procedure was adopted. First, the total torque loss $T_{\mathrm{T}}$ is measured under no load at a certain test condition. Then, the same test is repeated under a given transmitted torque $\left(T_{\mathrm{C}}\right)$ but with all other conditions remaining unchanged. When $T_{\mathrm{C}}=0, T_{\text {load-dependent }} \approx 0$, so in this case, $T_{\mathrm{T}} \approx T_{\text {load-independent }}$. Using Eq. (3), we can obtain the value of $T_{\text {load-dependent }}$ at the different values of $T_{C}$. In order to estimate the gear mesh torque loss, the load-dependent bearing torque loss must be removed from $T_{\text {load-dependent }}$ Load-dependent bearing loss is composed of rolling and sliding loss, which was estimated using Eq. (4) [20].

$T_{\text {bearing }}=M_{r r}+M_{\mathrm{sl}}$

$M_{r r}$ is the rolling friction moment:

$M_{r r}=\varphi_{\text {ish }} \varphi_{r s G_{r r}(v n)^{0.6}}$

$M_{\mathrm{sl}}$ is the sliding friction moment:

$M_{\mathrm{sl}}=G_{\mathrm{sl}} \mu_{\mathrm{sl}}$

The FZG gear test rig has a total of 8 NJ406 cylindrical roller bearings, four on the pinion side and four on the gear side. Bearing friction moment losses from the pinion side ( $\left.T_{\text {bearingSKF1 }}\right)$ and the gear side $\left(T_{\text {bearingSKF2 }}\right)$ were multiplied by the angular velocity of their respective shafts $\left(\omega_{1}\right)$ and $\left(\omega_{2}\right)$. The power losses for the eight bearings were then added together and divided by the ingoing angular velocity from the motor $\left(\omega_{2}\right)$ in the following manner:

$T_{\text {bearing }}=4\left(\frac{T_{\text {bearingSKF } 1} \omega_{1}+T_{\text {bearingSKF } 2} \omega_{2}}{\omega_{2}}\right)$

So the gear mesh torque loss $T_{\text {mesh }}$ can be obtained.
Table 5 The main parameters of gear specimens

\begin{tabular}{llll}
\hline & Symbol & Pinion & Gear \\
\hline Number of teeth & $z$ & 16 & 24 \\
Normal module $(\mathrm{mm})$ & $m_{n}$ & 4.5 & 4.5 \\
Gear width (mm) & $B$ & 14 & 14 \\
Pressure angle & $\alpha$ & $20^{\circ}$ & $20^{\circ}$ \\
Helix angle & $\beta$ & 0 & 0 \\
Base diameter $(\mathrm{mm})$ & $d_{\mathrm{B}}$ & 67.66 & 101.49 \\
Tip diameter $(\mathrm{mm})$ & $d_{\mathrm{a}}$ & 82.46 & 118.36 \\
Root diameter $(\mathrm{mm})$ & $d_{\mathrm{f}}$ & 61.34 & 98.98 \\
Centre distance $(\mathrm{mm})$ & $a$ & 91.500 & 91.500 \\
Tip relief $(\mu \mathrm{m})$ & $\mathrm{TR}$ & $20 \pm 3$ & $20 \pm 3$ \\
Start tip relief $(\mathrm{mm})$ & $d_{\mathrm{A}}$ & $80.3 \pm 0.3$ & $115.9 \pm 0.3$ \\
Gear quality class acc. to DIN 3961 & & 5 & 5 \\
RMS surface roughness $(\mathrm{gear}$ tooth) $(\mu \mathrm{m})$ & & 0.26 & 0.25 \\
\hline
\end{tabular}


Table 6 Efficiency test procedure of $\mathrm{AQ}-\mathrm{AQ}, \mathrm{RS}-\mathrm{AQ}$ and RS-RS gear combinations

\begin{tabular}{lll}
\hline Gear material combination & $\begin{array}{l}\text { Load (Nm) (load stage) } \\
\text { Contact pressure (MPa) }\end{array}$ & $\begin{array}{l}\text { Gear speed (rpm) } \\
\text { (pitch-line velocity (m/s)) }\end{array}$ \\
\hline & & $0(0)$ \\
& & $87(0.5)$ \\
& & $174(1)$ \\
AQ-AQ & 0 (LS 0) (0) & $348(2)$ \\
RS-AQ & $94.1($ LS 5) (900) & $550(3.2)$ \\
RS-RS & $183.4($ LS 7) (1080) & $1444(8.3)$ \\
& & $1740(10)$ \\
& & $2906(15)$ \\
\end{tabular}

$T_{\text {mesh }}=T_{\text {load-dependent }}-T_{\text {bearing }}$

\section{Experimental Results}

\subsection{Porosity Structure of AQ Material Gear and Pin}

Figure 4 shows optical micrographs of cut sections of the AQ material gear tooth and pin specimens showing pores on or near the surface of both specimens. Pores are typical characteristics of PM materials.

\subsection{SEM Micrographs of Pin Tip and Gear Flanks}

Figures 5 and 6 show the SEM micrographs of RS and AQ pins and gear flanks from different material combinations. The parallel traces visible in the SEM micrographs of pins indicate the same damage mechanism, i.e. scuffing. Pores on the surfaces of AQ pins can be seen clearly in the SEM pictures. As for the gears, all the gears were ground and the ground direction is labelled in the SEM photographs in Fig. 6. All the grooves in the grinding direction were caused during manufacturing. From Fig. 6, it can be seen that the gear teeth of the RS-RS combinations show heavier adhesive wear than the RS-AQ and AQ-AQ combinations. The gear teeth of RS-AQ show the lightest adhesive wear, that is, adhesive-wear-like material transfer but without scuffing compared to the RS-RS and AQ-AQ combinations.

\subsection{Gear Mesh Torque Loss and Friction Coefficient Results}

Figure 7 (left) shows the load-dependent torque losses for load stage 5 of the FZG gear rig efficiency tests for the AQ-AQ, RS-AQ and RS-RS material combinations. In addition, Fig. 7 (right) shows the pin-on-disc friction coefficient results with the same maximum contact pressure $(900 \mathrm{MPa})$ as that of the gear efficiency tests. At low pitch-line velocities (from 0.5 to $1 \mathrm{~m} / \mathrm{s}$ ), the trend of loaddependent torque loss of gear efficiency tests is the same as that of friction coefficient at low sliding speed $(0.5 \mathrm{~m} / \mathrm{s})$ of pin-on-disc experiment. AQ-AQ combination constantly shows the highest load-dependent torque loss and friction coefficient. At pitch-line velocity from 2 to $20 \mathrm{~m} / \mathrm{s}$, the trend of load-dependent torque loss is the same as that of friction coefficient at high sliding speed $(4 \mathrm{~m} / \mathrm{s})$ of pin-ondisc experiment. RS-AQ combination constantly shows the
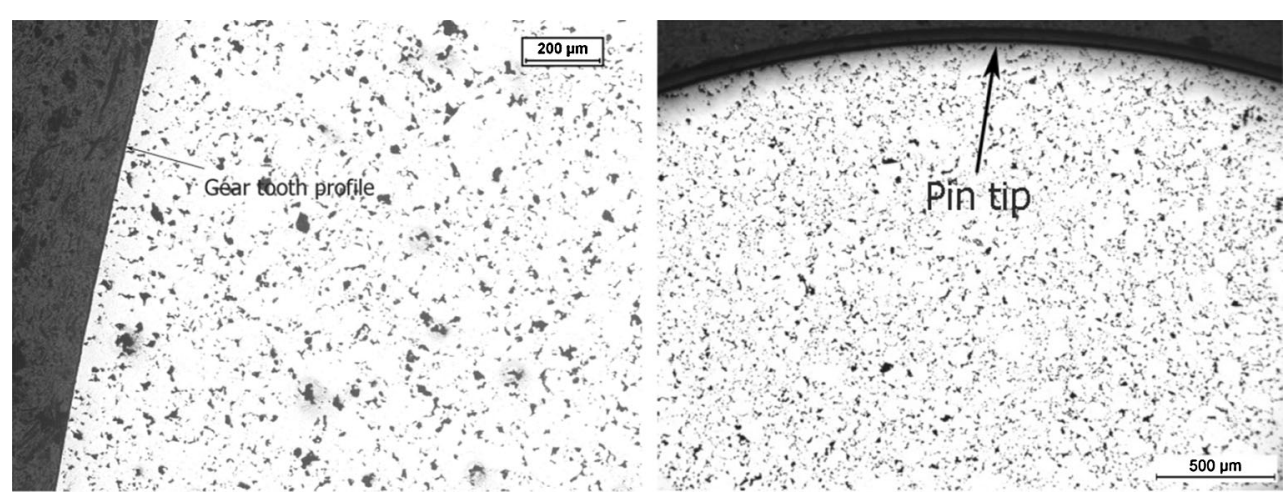

Fig. 4 Micrographs of cut section of AQ material: gear tooth (left) and pin (right) 


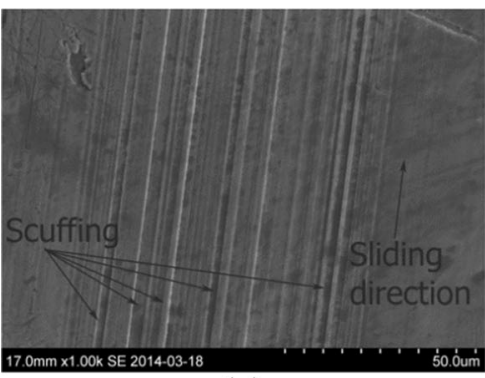

(a)

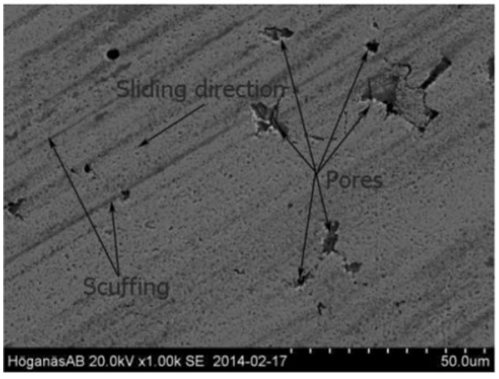

(d)

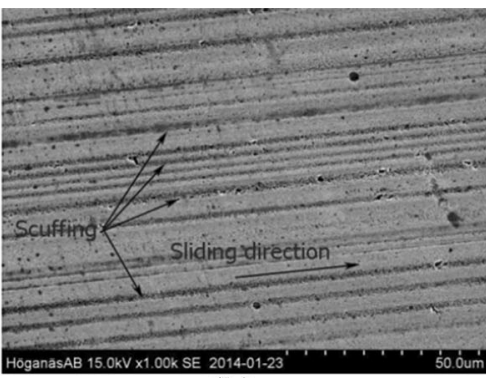

(b)

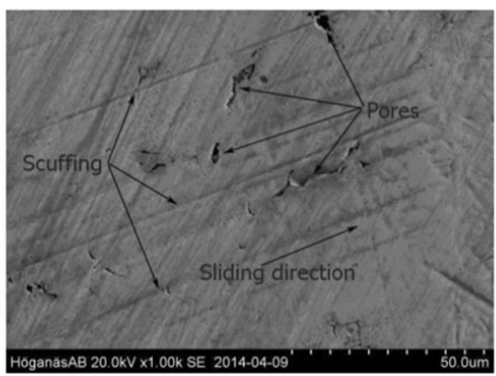

(e)

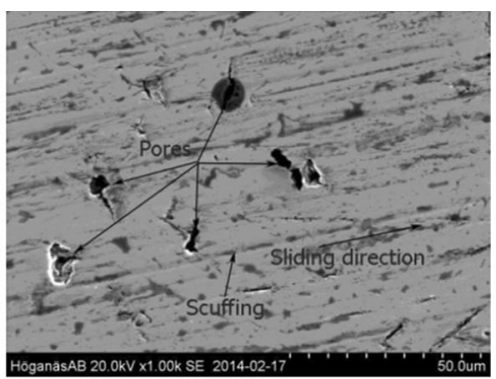

(c)

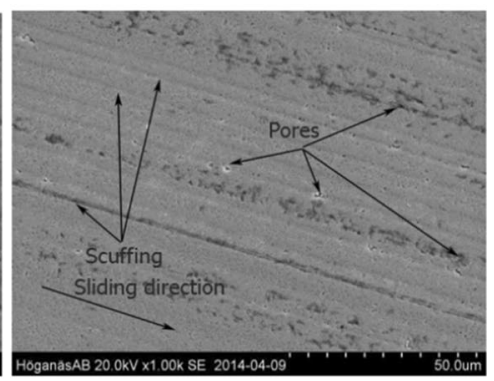

(f)

Fig. 5 SEM pin micrographs: a RS-RS 0.5 m/s, b RS-RS 4 m/s, c RS-AQ 0.5 m/s, d RS-AQ 4 m/s, e AQ-AQ 0.5 m/s, f AQ-AQ 4 m/s

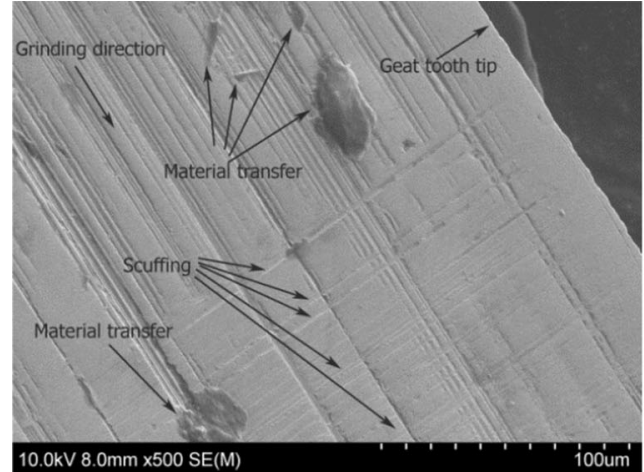

(a)

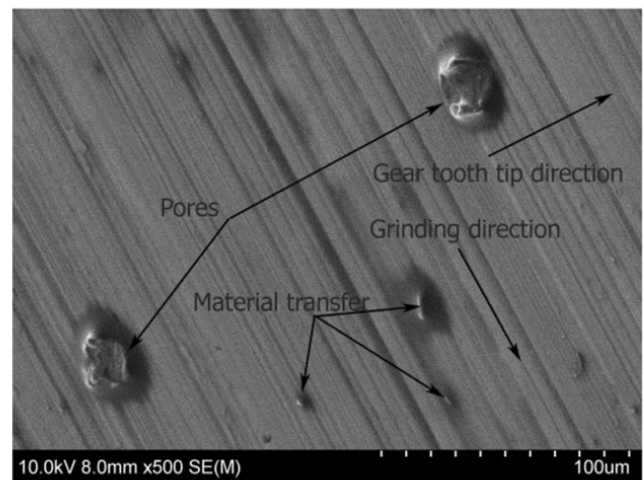

(c)

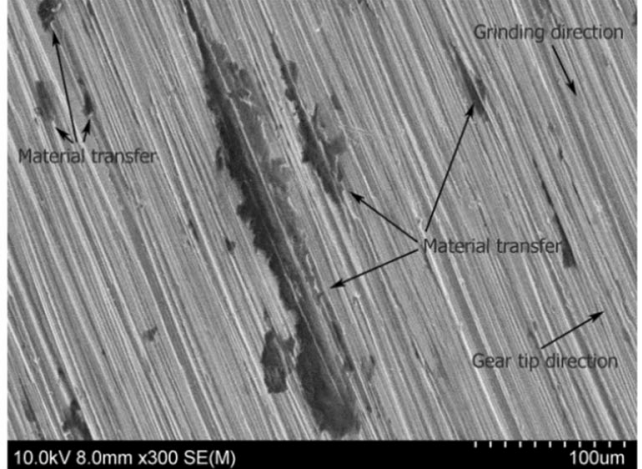

(b)

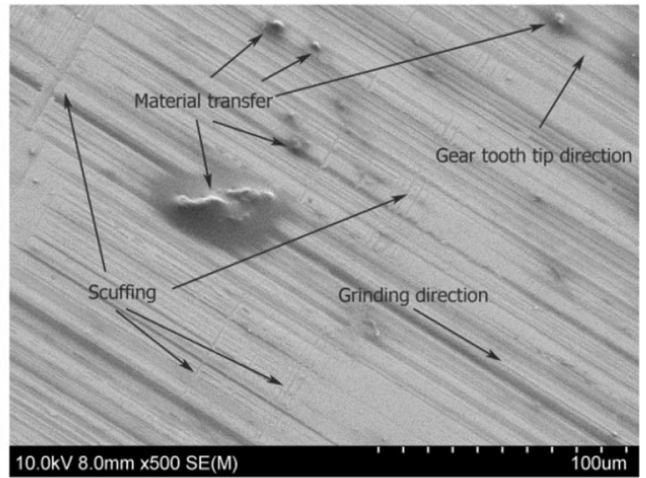

(d)

Fig. 6 SEM gear flank micrographs: a RS gear of RS-RS, b RS pinion of RS-RS, c AQ gear of RS-AQ, d AQ gear of AQ-AQ

lowest load-dependent torque loss and friction coefficient, and then, AQ-AQ and RS-RS had the highest gear mesh torque loss and friction coefficient.
In Fig. 8 (left), the gear mesh torque losses for load stage 7 are shown. Figure 8 (right) shows the pin-on-disc friction coefficient results at $1080 \mathrm{MPa}$. The friction 

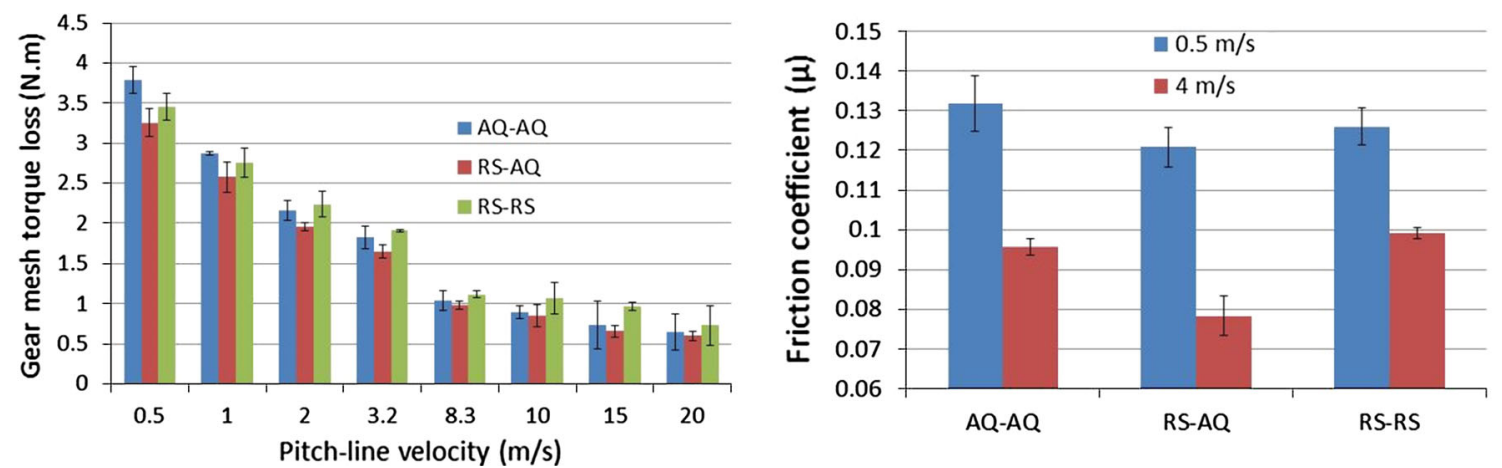

Fig. 7 FZG gear mesh torque losses for load stage 5 (left) and pin-on-disc friction coefficient results (right), contact pressure 900 MPa, of AQAQ, RS-AQ and RS-RS combinations. The error bars show the SD

coefficients of the AQ-AQ, RS-AQ and RS-RS material combinations are nearly the same at a sliding speed of $0.1 \mathrm{~m} / \mathrm{s}$. At a sliding speed of $0.5 \mathrm{~m} / \mathrm{s}$, the AQ-AQ material combination exhibits the highest coefficient of friction followed by the RS-AQ and RS-RS material combinations at about the same level. This is different from the results obtained at the lower contact pressure. For all the tested material combinations (AQ-AQ, RS-AQ and RS-RS) at $1080 \mathrm{MPa}$, the trend of gear mesh torque loss of the gear efficiency tests is the same as the friction coefficient $(0.5 \mathrm{~m} / \mathrm{s})$ of pin-on-disc experiment at pitch-line velocities of $0.5,1,2$ and $3.2 \mathrm{~m} / \mathrm{s}$. For the pitch-line velocities from 8.3 to $20 \mathrm{~m} / \mathrm{s}$, the RS-AQ combination shows the lowest gear mesh torque loss except at $15 \mathrm{~m} / \mathrm{s}$. The difference between AQ-AQ and RS-RS is not obvious.

\section{Discussion}

\subsection{FZG Gear Torque Loss and Pin-on-Disc Friction Coefficient at Contact Pressure of $900 \mathrm{MPa}$}

Martins et al. [6] measured the average friction coefficient of dip-lubricated FZG gears and reported that the friction

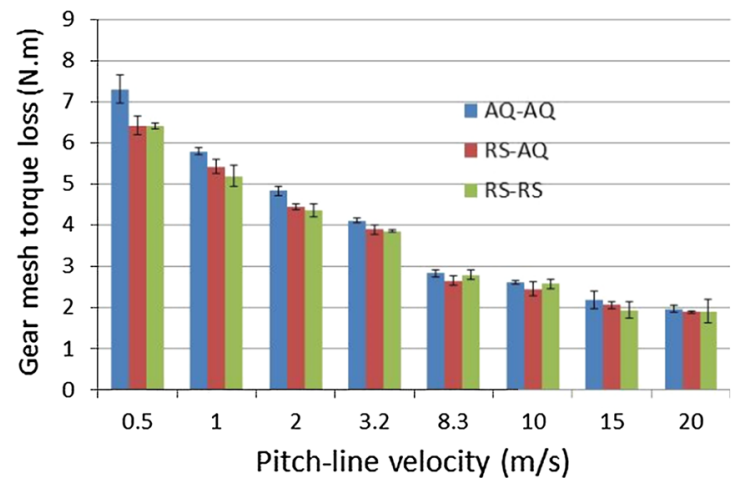

coefficient decreased with increasing rotational speed and increased with transmitted torque. A high/low friction coefficient also represents a high/low gear mesh torque loss. As shown in Fig. 7 left (low torque) and Fig. 8 left (high torque), the gear mesh torque loss shows the same result as [6], that is, the gear mesh torque loss decreases with increasing rotational speed and increases with transmitted torque.

From pitch-line velocity 0.5 to $20 \mathrm{~m} / \mathrm{s}$, the value of the gear mesh torque loss of the RS-AQ gear combination is consistently the smallest (Fig. 7). The porosity structure of the AQ gear and AQ pin in Fig. 4 shows that there are porosities on the surfaces of the AQ gear tooth and pin. Furthermore, we can also see pores on the surfaces of the AQ pin tip in Fig. 5c-f. The low gear mesh torque loss and friction coefficient of RS-AQ combination are mainly due to the porosities on the surfaces of the AQ parts, which act as oil reservoirs to supply enough lubricant to lubricate the contact surfaces. References [10-12] show that controlled dimples on contact surfaces act as lubricant reservoirs and play a role in promoting better lubrication and a decrease in friction. By calculation, the size (average value of length and width) of pores in the AQ pin and gear tooth is between 30 and $40 \mu \mathrm{m}$. The surface textures in Wakuda [10] and Kovalchenko [12] are in the form of circular dimples with

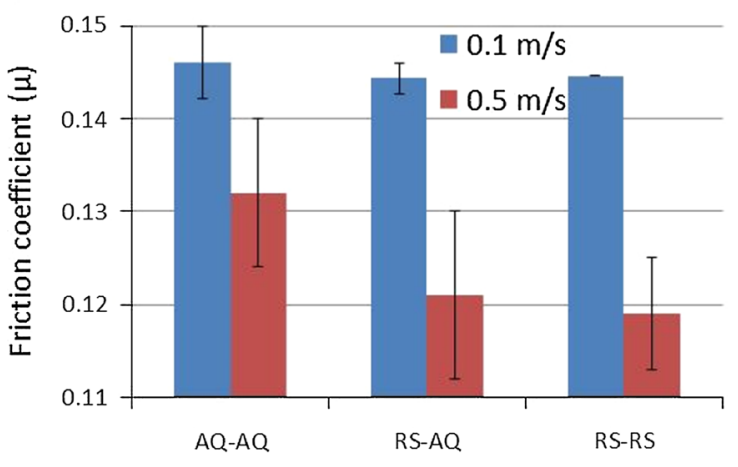

Fig. 8 FZG gear mesh torque losses for load stage 7 (left) and pin-on-disc friction coefficient results (right), contact pressure $1080 \mathrm{MPa}$, of AQAQ, RS-AQ and RS-RS combinations. The error bars show the SD 
diameters of 58, $78 \mu \mathrm{m}$ and 40, $80120 \mu \mathrm{m}$, respectively. For Pettersson [11], there are two different surface textures: the first is in the form of grooves 5,20 and $50 \mu \mathrm{m}$ wide, and the second one is grids with the same length and widths of 5, 20 and $50 \mu \mathrm{m}$. There are some differences between the size of the porosities of the AQ gear tooth and pin with the porosities in [10-12], but the sizes are not that different. Wakuda [10] recommended a dimple size of approximately $100 \mu \mathrm{m}$ under the tested friction conditions. Pettersson [11] showed that the 5- and $20-\mu \mathrm{m}$ grooved textures and the surface with $5-\mu \mathrm{m}$ depressions exhibited good frictional properties for all 200,000 cycles. Kovalchenko [12] showed that circular dimples of 58 and $78 \mu \mathrm{m}$ reduced the friction coefficient substantially. In this research, the gear mesh torque loss and friction coefficient results for the AQ material gear tooth and pin with pores sized 25 to $35 \mu \mathrm{m}$ show the same behaviour as that of [10-12], that is, the pores on the surfaces of the AQ components act as lubricant reservoirs enabling good lubrication.

Van Beek [9] showed that different material combinations can prevent adhesive wear and so enhance transmission efficiency indirectly. It is obvious in Figs. 5 and 6 that abrasive-wear-like scuffing occurred on all the surfaces of both the AQ and RS gear tooth and pins. However, there is heavy abrasive-wear-like scuffing and material transfer on the surfaces of the pins and gear teeth of the RS-RS combination. As with the AQ gear tooth and pin of AQ$\mathrm{AQ}$ and RS-AQ combinations, there is adhesion, but only a little scuffing and material transfer compared to the RS-RS combination. So the reduced adhesive wear of the different material combination and existence of alloys in the AQ materials indirectly enhance transmission efficiency.

When two smoothly finished surfaces of the same material are forced together, the surface energy is completely determined by the adhesive energy, $\gamma_{a b}=0$, $T_{a b}=2 \gamma_{a}=2 \gamma_{b}$. With two different materials, some interface energy remains, reducing the adhesive energy that is released. Alloys are generally beneficial in respect of friction, regardless of the alloying element, because they reduce the surface energy $\gamma$ and increase hardness. Thus, another reason for the lower gear mesh torque loss and friction coefficient in the AQ components is the different material combination and the presence of the alloy element nickel. The main reason that the RS-AQ combination shows both lower gear mesh torque loss and a lower friction coefficient is probably that the porosities on the surfaces of the AQ material component act as oil reservoirs to supply enough lubricant to lubricate the contact surfaces. In addition, the different material combination can reduce the released adhesive energy, and the alloy reduces the surface energy in the AQ components [9].

The AQ-AQ combination shows the highest load-dependent torque loss at lower pitch-line velocities of 0.5 and
$1 \mathrm{~m} / \mathrm{s}$ and the highest friction coefficient at sliding speed of $0.5 \mathrm{~m} / \mathrm{s}$ (Fig. 7). This is mainly because the pores on the surface of AQ components act as surface roughness at low sliding speeds. Pettersson [11] also showed that the $50-\mu \mathrm{m}$ textures could not sustain the low friction and suffered severe wear at somewhat lower speed. Above a pitch-line velocity of $2 \mathrm{~m} / \mathrm{s}$, the AQ-AQ combination consistently shows lower gear mesh torque loss than the RS-RS combination, and the friction coefficients at high sliding speed $(4 \mathrm{~m} / \mathrm{s})$ show the same trend as the gear mesh torque loss. The lower gear mesh torque loss and friction coefficient of the AQ-AQ combination at high speed are mainly caused by pores on the surface of $\mathrm{AQ}$ component that act as oil reservoirs [10-12] and by the existence of alloying elements that reduce the surface energy [9].

\subsection{FZG Gear Torque Loss and Pin-on-Disc Friction Coefficient at Contact Pressure of $1080 \mathrm{MPa}$}

Figure 8 shows that at speeds from 0.5 to $3.2 \mathrm{~m} / \mathrm{s}$, both the gear mesh torque loss and the friction coefficient at $0.5 \mathrm{~m} / \mathrm{s}$ of AQ-AQ and RS-AQ are higher than that of the RS-RS combination. The main reason is probably that the porosities on the AQ component act as surface roughness, providing more opportunities for asperity contact [13]. Pettersson [11] also showed that the 50- $\mu \mathrm{m}$ textures could not maintain low friction and suffered severe wear, showing the same frictional trend as the AQ-AQ and RS-AQ combinations. The friction coefficient at $0.1 \mathrm{~m} / \mathrm{s}$ of the three different material combinations is nearly the same (Fig. 8 right). The pin-on-disc tests of Kovalchenko [12] showed that the beneficial effects of micro-dimples are more pronounced at higher speeds with higher viscosity oil. Thus, the effect of the porosities on the surfaces of AQ components acting as oil reservoirs may be dependent on speed and lubricant viscosity. Further study is needed to determine the relationships between porosity, speed and lubricant viscosity. The RS-AQ showed a higher gear mesh torque loss and friction coefficient than that of the RS-RS. Although different material combination can prevent adhesive wear [9], surface roughness caused by porosity dominated at heavy load. Above a pitch-line velocity of $8.3 \mathrm{~m} / \mathrm{s}$, the gear mesh torque loss of RS-AQ is the smallest except at $15 \mathrm{~m} / \mathrm{s}$. The main reason is probably that the porosities on the surfaces of the AQ material component act as oil reservoirs that lubricate the contact surfaces at higher speeds [10-12]. In addition, the different material combination can reduce the released adhesive energy, and the alloy reduces the surface energy in the AQ components [9]. The AQ-AQ and RS-RS combinations had nearly the same gear mesh torque loss between pitchline velocities of 8.3 and $20 \mathrm{~m} / \mathrm{s}$ except at $15 \mathrm{~m} / \mathrm{s}$. 


\section{Conclusions}

The RS-AQ gear combination is a good candidate for gear transmissions at medium to high pitch-line velocities because the porosities of the AQ act as oil reservoirs that enable good lubrication conditions; the different material combinations can prevent adhesive wear, and the existence of the alloying element reduces the surface energy in the AQ component.

The porosities on the surfaces of AQ components that act as oil reservoirs are speed and load-dependent. The higher the speed and lower load, the better the effect of the pores act as oil reservoirs.

The trend in gear mesh torque loss is the same as that of the friction coefficient of the pin-on-disc experiment. Pinon-disc experiment simulates the sliding part of gear mesh successfully, and friction coefficient of it can reflect the trend of gear mesh torque loss.

At low speed and heavy load, the porosities of AQ (both gear and pin) act as surface roughness to enhance the opportunities for asperity contact.

Acknowledgments We would like to thank Dr. Michael Andersson and Persson Marcus from Höganäs $\mathrm{AB}$ for their valuable discussion and technological support. This project was financially supported by Höganäs AB.

\section{References}

1. Michaelis, K., Höhn, B.-R., Hinterstoisser, M.: Influence factors on gearbox power loss. Ind. Lubr. Tribol. 63(1), 46-55 (2011)

2. Petry-Johnson, T., Kahraman, A., Anderson, N.E., Chase, D.: An experimental investigation of spur gear efficiency. J. Mech. Des. 130, 062601-1 (2008). doi:10.1115/1.2898876

3. Naruse, C., Haizuka, S., Nemoto, R., Kurokawa, K.: Studies on frictional loss, temperature rise and limiting load for scoring of spur gears. Bull. JSME 29, 600-608 (1986)

4. Naruse, C., Nemoto, R., Haizuka, S., Takahashi, H.: Influences of tooth profile in frictional loss and scoring strength in the case of spur gears. JSME International Conference on Motion and Power Transmissions, Hiroshima, Japan, pp. 1078-1083 (1991)
5. Magalhes, L., Martins, R., Locateli, C., Seabra, J.: Influence of tooth profile and oil formulation on gear power loss. Tribol. Int. 43(10), 1861-1871 (2010)

6. Martins, R., Seabra, J., Brito, A., Seyfert, Ch., Luther, R., Igartua, A.: Friction coefficient in FZG gears lubricated with industrial gear oils: biodegradable ester vs. mineral oil. Tribol. Int. 39, 512-521 (2006)

7. Britton, R.D., Elcoate, C.D., Alanou, M.P., Evans, H.P., Snidle, R.W.: Effect of surface finish on gear tooth friction. Trans. ASME 122, 354-360 (2000)

8. Suh, N.P., Sin, H.C.: The genesis of friction. Wear 69, 91-114 (1981)

9. Van Beek, A.: Advance Engineering Design, pp. 155-158. TU Delft (2009)

10. Wakuda, M., Yamauchi, Y., Kanzaki, S., Yasudac, Y.: Effect of surface texturing on friction reduction between ceramic and steel materials under lubricated sliding contact. Wear 254(3-4), 356-363 (2003)

11. Pettersson, U., Jacobson, S.: Influence of surface texture on boundary lubricated sliding contacts. Tribol. Int. 36(11), 857-864 (2003)

12. Kovalchenko, A., Ajayi, O., Erdemir, A., Fenske, G., Etsion, I.: The effect of laser surface texturing on transitions in lubrication regimes during unidirectional sliding contact. Tribol. Int. 38(3), 219-225 (2005)

13. Li, X., Sosa, M., Olofsson, U.: A pin on disc study of the tribology characteristics of sintered versus standard gear materials. In 16th Nordic Symposium on Tribology, Århus, Denmark (2014)

14. Beiss, P.: Mechanische eigenschaften von sinterstählen. Tagungsband zum Symposium für Pulvermetallurgie: MaterialProzess-Anwendung Hagen 27 (2003)

15. Zhu, Y., Olofsson, U., Chen, H.: Friction between wheel and rail: a pin-on-disc study of environmental conditions and iron oxides. Tribol. Lett. (2013). doi:10.1007/s11249-013-0220-0

16. Bergseth, E., Torbacke, M., Olofsson, U.: Wear in environmentally adapted lubricant with AW technology. J. Synth. Lubr. 25, $137-158$ (2008)

17. Winter, H, Michaelis, K.: FZG gear test rig: description and possibilities. In: Coordinate European Council Second International Symposium on The Performance Evaluation Of Automotive Fuels And Lubricants (1985)

18. Sjöberg, S., Sosa, M., Andersson, M., Olofsson, U.: A study of running-in and efficiency of ground gears. Tribol. Int. (accepted)

19. Andersson, M., Sosa, M., Sjöberg, S., Olofsson, U.: Effect of assembly errors in back-to-back gear efficiency testing. In: International Gear Conference, Lyon, France (2014). doi:10. 1533/9781782421955.784

20. SKF, Rolling Bearing Catalogue, pp. 97-114 (2012) 